\title{
Endocrinology of the lactating and weaned sow
}

\author{
M. A. Varley and G. R. Foxcroft* \\ Department of Animal Physiology and Nutrition, University of Leeds, Leeds, UK; and \\ * Department of Animal Science, University of Alberta, Edmonton, Alberta T6G 2P5, Canada
}

Keywords: lactation; weaning; sow; endocrinology; suckling

\section{Introduction}

Lactation represents an unproductive time in the reproductive cycle when there is little opportunity for initiating the next pregnancy. The neuroendocrine inhibition of the ovaries by the suckling stimulus prevents an early post-partum ovulation and the lactating sow concentrates her metabolic effort on the production of milk for the rapidly growing litter. In late lactation the sow overcomes the inhibitory effects of suckling and several experiments have shown that sows can be mated before weaning (Crighton, 1970; Rowlinson \& Bryant, 1982). The successful mating of lactating females in early lactation has, however, proved difficult. The achievement of this goal would offer significant advantages to on-farm management and the reproductive output from gilts and sows.

The time from parturition to weaning is a relatively short period but the expectation is that breeding females produce a litter of 10-12 piglets, deliver a nutritional package to this litter over the course of the 3-4 weeks of lactation and at the end of this short interval exhibit oestrus and ovulate within 5 days of weaning. In the first 7-10 days after parturition uterine involution and endometrial repair take place and evidence suggests that the uterus is ready to sustain another successful gestation shortly after this time (Hughes \& Varley, 1980). Ovarian function through lactation has been examined by a number of workers (Burger, 1952; Palmer et al., 1965) and it was reported that the ovaries are usually quiescent unless an exceptionally long lactation allows follicular growth. More recent observations (Edwards, 1982; Kunavongkrit, 1984) have shown that following parturition and the initiation of lactation the ovaries remain dormant for perhaps 10 days. After this time small follicles may begin to develop although none attains the size of Graafian follicles (see review of Britt et al., 1985).

Many hormones are involved in the initiation and maintenance of lactation. Prolactin and oxytocin may be the dominant lactogenic factors but growth hormone and hormones from the thyroid and adrenal glands are also involved. As a direct consequence of parturition there are profound endocrine changes which, when coupled with the endocrine events associated with the onset of suckling, lead to the initiation of lactation and the effective suppression of follicular growth. In the absence of a suckling stimulus immediately after parturition (zero weaning) the ovaries are not effectively controlled and acute endocrine dysfunction ensues. Several studies with zero-weaned sows have elucidated the endocrine signals involved (Kunavongkrit, 1984; Varley \& Atkinson, 1985; de Rensis, 1989) and these will be reviewed.

Producers to some extent circumvent the problem of achieving concurrent pregnancy and lactation by early weaning (Varley, 1982) but in many respects the adoption of early weaning is not compatible with the need to improve the welfare of our farm livestock. Early weaning involves the use of intensive housing systems for the weaned piglets and breeding sows spending more time in sow stalls. If it were possible to achieve predictable concurrent pregnancy and lactation within a few days after parturition, sows could then spend considerably more of their time in nonconfinement building systems (multi-suckling areas) and still produce 2.5 litters per year. A number of techniques such as split and partial weaning have been examined which have the potential to 
improve the endocrine function of the sow before and after weaning. These techniques require rigorous evaluation before deployment in commercial practice.

Over the course of the past few years there has been a vigorous effort to acquire a better understanding of the endocrine events controlling reproduction in lactating and weaned sows. The purpose of this paper is to present an overview of recent work in this area, to collate our existing knowledge and to establish guidelines for future work.

\section{The induction of concurrent pregnancy and lactation}

Various techniques have been deployed over the years in an attempt to achieve successful concurrent pregnancy and lactation which, in most cases, have been defeated by the sheer intractability of lactational anoestrus. In general, the induction of concurrent pregnancy and lactation has been moderately successful only after the 3 rd week of lactation. The methods used have included partial weaning (Crighton, 1970; Newton et al., 1987), social grouping and boar exposure (Rowlinson \& Bryant, 1982; Duggan et al., 1982), gonadotrophin treatment (Ahrens \& Schlegel, 1975; MartinatBotte, 1975; Schumm et al., 1979; Hausler et al., 1980), oestrogen treatment (Elsaesser \& Parvizi, 1980; Cox et al., 1988), GnRH administration (Guthrie et al.. 1978; Cox \& Britt, 1982; Rojanasthien et al., 1987) and opioid modulation (Barb et al., 1987).

One of the most interesting methods involved the regrouping of sows and litters at about the 10th day of lactation followed by boar exposure on Day 11. In the study of Rowlinson \& Bryant (1982), this method yielded $100 \%$ of sows in oestrus at an average of 34.1 days after farrowing with a subsequent litter size of 11.1 piglets. Duggan et al. (1982) using a similar protocol demonstrated elevated plasma concentrations of LH after treatment, but these data were generated from a single herd. Attempts to repeat these results on other farms has not met with similar success (Petchey \& English, 1980).

Britt et al. (1985) reviewed experiments concerned with the application of gonadotrophins to lactating sows. It appears the later in lactation that gonadotrophins are used the better the response: $14 \%$ of sows responded to treatment between the 1 st and the 5 th day of lactation whereas treatment between 30 and 36 days post partum produced a $64 \%$ and $72 \%$ response, respectively.

The possibility of giving oestradiol benzoate as a means of stimulating an LH response and ovulation has been investigated in a number of studies. Cox et al. (1988) gave oestradiol benzoate at the end of the 2 nd, 3 rd or 4 th weeks of lactation. Only 1 sow out of 4 in the first group and 4 out of 5 sows in each of the other groups showed oestrus. Only one animal ovulated in the experiment (oestradiol treatment at the end of the 2 nd week). Data on LH concentrations indicated that there had been a partial recovery of the positive feedback of oestrogen by the end of the 4th week of lactation. This confirms an earlier observation made by Elsaesser \& Parvizi (1980) that 4 out of 9 animals given oestradiol benzoate 35 days post partum showed elevated progesterone concentrations following injection indicative of induced ovulation.

Guthrie et al. (1978) completed 3 experiments using boar contact, gonadotrophins or GnRH injections to induce lactational oestrus and ovulation. Boar contact failed to induce oestrus in 23 crossbred sows and only 2 ovulated. In a second experiment these same authors used a combination of PMSG and hCG given 12-14 days post partum. The sows were then given a single injection of GnRH $72 \mathrm{~h}$ later. Of the sows given GnRH in this way, 8 of 15 sows ovulated and 5 of 15 had fertilized eggs. In a third experiment in which sows were allowed to progress to full term, only 12 of 53 treated sows farrowed following $\mathrm{Gn} / \mathrm{GnRH}$ treatment.

Cox \& Britt (1982) administered pulsatile GnRH at the rate of $2.5 \mu \mathrm{g}$ every $2 \mathrm{~h}$ to lactating sows from Day 24 of lactation for 7 days: $50 \%$ of treated sows showed oestrus 4 days after the beginning of treatment, and all became pregnant. In a second experiment in which 11 sows were given a lower dose of $1.5 \mu \mathrm{g}$ GnRH every hour for 7 days from Day 31 of lactation, all sows showed oestrus (average 3.8 days later) after GnRH treatment and $85 \%$ of sows conceived. A similar high rate of 
response was reported by Ramirez et al. (1985) using the same treatment schedule from Day 24 of lactation. Pulsatile administration of GnRH during lactation therefore was associated with requisite hormonal events for fertile oestrus to occur.

There has been recent interest in the role of opioids and their antagonists in the control of ovulation. Acute administration of morphine at 25 days post partum prevented the increase in $\mathrm{LH}$ secretion associated with partial weaning and chronic administration of morphine delayed the onset of oestrus after weaning, presumably through suppression of LH secretion (Armstrong et al., 1988b). In the work of Barb et al. (1987), naloxone was given to post-partum sows and serum concentrations of LH increased to those seen in weaned sows within $1 \mathrm{~h}$ of treatment. Serum prolactin in lactating sows given naloxone decreased but not to the basal levels seen in weaned sows. Armstrong et al. (1988a), Barb et al. (1986) and Mattioli et al. (1986) have also given naloxone to lactating sows and found that, after naloxone infusion, episodic release of $\mathrm{LH}$ increased and concentrations of peripheral prolactin decreased. It seems therefore that the endogenous opioid peptides are intimately involved in the inhibition of LH and FSH secretion and/or release during lactation.

\section{Steroid hormones}

Steroid hormones are at low levels and are generally assumed to play a minor role in the inhibition of reproductive activity throughout lactation; indeed ovariectomy in lactation had no effect on $\mathrm{LH}$ secretion (Stevenson et al., 1981). Progesterone exerts feedback activity throughout pregnancy and modulates the production and release of gonadotrophin from the anterior pituitary gland. This 'luteal' influence is replaced in lactation by the tactile stimuli associated with suckling, as described later.

Work with early-weaned sows has shown that a minimum period of suckling may be needed to allow the complete recovery of the hypophysial/gonadal axis from the prolonged influence of gestation. Varley (1982) concluded that, when lactation is limited to less than 3 weeks, there is a significant increase in the weaning to oestrus interval and in embryos lost during the first 3 weeks of pregnancy after mating. However, this work also demonstrated that in the first 10 days post coitum the early-weaned sow has peripheral concentrations of progesterone which are identical to those of sows having lactations of around 5 to 6 weeks. During the first few days of pregnancy, however, oestrogen concentrations may be abnormally high and variable in early-weaned sows. Varley et al. (1981) reported that peripheral oestradiol-17 $\beta$ concentrations in sows weaned after 10-day lactations exceeded $200 \mathrm{pg} / \mathrm{ml}$ at 4 days post coitum. This work was extended by Varley et al. (1984) who studied three groups of sows weaned after lactations of 10,21 or 42 days. Blood samples were taken between weaning and 10 days post coitum and oestradiol-17 $\beta$ concentrations were higher in early-weaned sows throughout this period. At slaughter at 24 days post coitum, the embryo survival rates of all sows in the 10-day weaned group were lower $(63.8 \%)$ than in the sows in the 42-day weaned group ( $77 \%$ ), thus substantiating earlier work (Varley \& Cole, 1978; Svajgr et al., 1974). There was, however, no significant relationship between the oestradiol concentrations and embryo survival, although sows in the 21 - and 42-day groups with the highest mean values of oestradiol tended also to have the poorest embryo survival. It was also noted that many sows had elevated oestradiol concentrations on the day of weaning implying that oestradiol values must have been well above baseline during lactation.

More recently work has been carried out with zero-weaned sows in which the normal endocrine changes associated with the initiation of lactation and the post-weaning follicular phase are superimposed on each other such that the whole system is disrupted. Nevertheless, follicles present in the ovary at the end of pregnancy grow rapidly under the stimulus of pituitary LH and FSH (Peters et al., 1969b; Elliot et al., 1980; Kunavongkrit et al., 1983a, b; Varley \& Atkinson, 1985; Buttle, 1987). However, the limited LH surge response to secreted oestrogens may fail to induce downregulation of $\mathrm{LH}$ receptors, an associated fall in oestrogen synthesis and normal luteinization; 
consequently many zero-weaned sows develop large cystic and oestrogenically active follicles. This is associated with elevated plasma oestrogen, a high percentage of sows either becoming anoestrous or showing constant oestrus after zero-weaning and a high level of embryo mortality in sows that are successfully mated (Peters et al., 1969b; Elliot et al., 1980; Kunavongkrit et al., 1983a, b; Kunavongkrit, 1984; Varley \& Atkinson, 1985).

Plasma progesterone determinations in the study of Varley \& Atkinson (1985) indicated that although a majority of sows remained anoestrous or did not show oestrus until after Day 30 post partum, $28 \%$ of them had silent heats $13.8 \pm 0.7$ days after parturition and in a further $38 \%$ oestrus and ovulation occurred 12.1 $\pm 1 \cdot 2$ days after parturition. Thus around two-thirds of zero-weaned sows ovulated at about 2 weeks after parturition despite the high incidence of nymphomania, anoestrus and prolonged weaning-to-oestrus intervals. Oestrogen concentrations in zeroweaned sows were extremely variable and generally high in the immediate post-partum period, but there was no obvious relationship between oestradiol levels and the incidence of anoestrous behaviour or nymphomania. Kunavongkrit (1984) has also examined the endocrine profiles of zeroweaned sows and reported elevated cortisol concentrations in addition to high oestrogens and a lack of any LH peak during oestrus in sows which developed ovarian cysts.

In an attempt to normalize reproductive function by replacing the suckling-induced inhibition of the hypophysial axis with a progestagen signal in zero-weaned sows, allyl-trenbolone was given daily for 10 days after parturition to sows which were weaned at birth (M. A. Varley \& T. Atkinson, unpublished). These sows were compared with sows which suckled for 10 days and zeroweaned sows given no exogenous hormones. The use of allyl-trenbolone effectively replaced the suckling stimulus as an early post-partum inhibitor of ovarian function. Although this could be an appropriate means for controlling oestrus and ovulation in zero-weaned sows, progestagen treatment significantly delayed uterine involution and this could be a principal factor in the poor embryo survival rates seen in those progestagen-treated zero-weaned sows that were mated. The concentrations of oestradiol-17 $\beta$ in zero-weaned sows treated with allyl-trenbolone were not significantly different from zero-weaned sows not given exogenous hormone treatment, although the former group of sows had lower levels overall.

The work cited above emphasizes that higher circulating concentrations of oestradiol may be present in the early post-partum sow. This might be expected in zero-weaned sows with their propensity for cystic ovarian conditions but suckled sows weaned after lactations of 10-20 days are also reported to display high oestrogen concentrations at weaning.

To substantiate such reports M. A. Varley \& T. Atkinson (unpublished data) bled 15 sows from parturition through a 42-day lactation, during the post-weaning period to mating and up to 10 days post coitum. The objective was to elucidate oestrogen activity throughout lactation and also to examine whether elevations of peripheral oestrogen have any relationship with either prolonged weaning to oestrus intervals or to the incidence of anoestrus after weaning. Progesterone concentrations in this experiment were basal throughout the 6-week lactation although there was a significant but small rise at 28 days post partum (Fig. $1 \mathrm{a}, \mathrm{b}$ ), which has also been reported by Ash \& Heap (1975). None of the sows ovulated or showed heat spontaneously during lactation but it may be that at the end of the 4th week of lactation, many sows partly escaped the inhibitory effects of the suckling stimulus. Oestradiol-17 3 concentrations in this study are shown in Fig. l(b). Although concentrations fell rapidly initially after parturition, they did not remain low throughout lactation. Although plasma oestradiol concentrations were extremely variable, there was a tendency for an increase around 3 weeks post partum at the time of peak lactation. None of the sows in this experiment became anoestrous after weaning and there was no apparent relationship between the pattern of oestrogen secretion and prolonged weaning to oestrus intervals.

These observations contrast with the reports of Ash \& Heap (1975) and with Stevenson \& Britt (1980) who have observed that oestrogen concentrations did not rise above $10 \mathrm{ng} / \mathrm{l}$ and $50 \mathrm{ng} / \mathrm{lin}$ lactation, respectively. There are, however, other reports in the literature of elevated oestrogen concentrations in lactation. Shearer et al. (1972), Edqvist et al. (1974), Kirkwood et al. (1984) and 

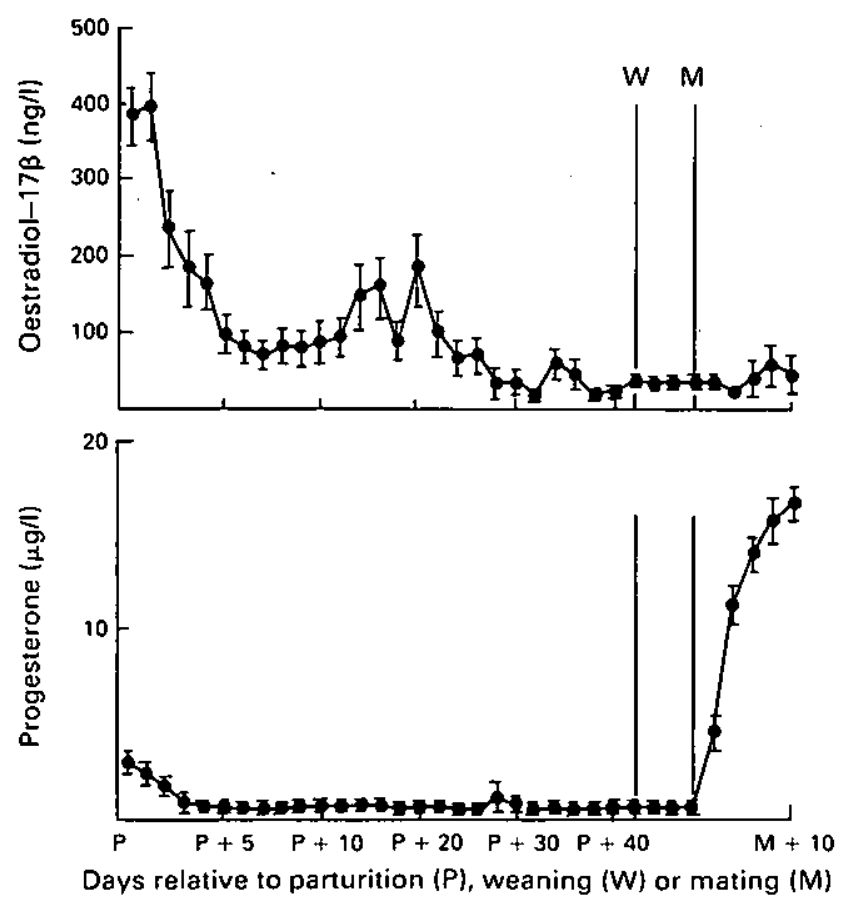

Fig. 1. Mean ( \pm s.e.m.) plasma concentrations of (a) oestradiol-17 $\beta$ and (b) progesterone in sows $(\mathrm{N}=15)$ between parturition and 10 days post coitum (M. A. Varley \& $\mathrm{T}$. Atkinson, unpublished observations).

McDonald (1975) have all observed variable peaks of oestrogens during lactation. The intensity and magnitude of these changes, however, differs; in the work of M. A. Varley \& T. Atkinson (unpublished) $87 \%$ of sows had elevated concentrations of oestrogen, but $30 \%$ of sows in the study by Edqvist $e t$ al. (1974) showed elevated (up to $440 \mathrm{pg} / \mathrm{ml}$ ) oestradiol- $17 \beta$ values.

The source of oestrogens in lactation has not been established but in the light of observations made by Burger (1952), Palmer et al. (1965) and Edqvist et al. (1974) it seems that although a limited amount could be produced from the ovaries, the relatively small follicular structures seen in mid-lactation would be unlikely to produce the quantities reported. Stevenson et al. (1981) have also found that ovariectomized gilts had comparable oestradiol levels to those in intact gilts during lactation, suggesting an extra-ovarian source of lactational oestrogen. One possibility is that body fat stores retain significant quantities of lipophilic steroids and that as a consequence of body weight loss in lactation these same steroids could be released into the general circulation. Hillbrand \& Elsaesser (1983) have shown that fat stores can contain 200 times the amount of steroid in the peripheral circulation and this figure has been confirmed by Prime et al. (1988).

A further possibility is that lactational oestrogen could originate from the adrenal cortex. Work in other species (Brown et al., 1959) has shown that the adrenal glands can be a source of considerable quantities of oestrogens and the putative factor involved in the synthesis and release of such oestrogens is stress. If stress is a factor in the appearence of high levels of oestrogens during lactation then this might explain why the response is so variable and unpredictable. There is considerable between-herd variation and also between-animal variation in oestrogen production and it may be that some animals and farms are predisposed to stress and the stressors themselves will vary greatly between farms. 


\section{Gonadotrophin secretion during lactation}

The main conclusions drawn from earlier reviews of this topic (Britt et al., 1985; Foxcroft, 1985) can be summarized as follows.

(1) The inhibition of LH and FSH secretion is the principal cause of lactational anoestrus.

(2) The inhibition of episodic $\mathrm{LH}$ release and in part in FSH secretion results from the inhibition of GnRH synthesis and release; however, FSH suppression also involves a non-steroidal ovarian regulator, probably inhibin.

(3) Whilst the inhibition of GnRH release is probably mediated by suckling-induced neuroendocrine reflexes, neither prolactin nor oxytocin have clearly established inhibitory effects on hypothalamic GnRH secretion.

(4) During lactation, a progressive release from the inhibitory effects of suckling/lactation is seen; this may be directly related to a reduction in suckling frequency and milk synthesis or to a gradual recovery of the hypothalamic/hypophysial/ovarian axis from the suppressive effects of pregnancy.

(5) Considerable variability exists between sows in the extent to which gonadotrophin secretion and ovarian function are suppressed during lactation; increased episodic release of $\mathrm{LH}$ in particular is generally positively related to enhanced follicular development in lactation and an early return to oestrus after weaning.

(6) The absence of enhanced follicular growth, even in the presence of increased gonadotrophin secretion after weaning in some sows, indicates that other factors may exert an important influence on ovarian function.

Such conclusions will now be reviewed in the context of recent studies in lactating and weaned sows.

The ontogeny of the suppression of gonadotrophin secretion during lactation merits discussion.

In the sow, as in other species, the dysfunction of the oestrogen-positive feedback mechanism in early lactation is considered to be a consequence of the prolonged exposure of the hypothalamic/ pituitary axis to high levels of progesterone during gestation (Elsaesser \& Parvizi, 1980). With reference to data from ruminants, Nett (1987) presented a compelling case for similar latent effects of pregnancy on the tonic secretion of gonadotrophins in the early post-partum period. In a number of respects this situation initially appears to be applicable to the sow. Melampy et al. (1966) reported that pituitary $\mathrm{LH}$ concentrations reached a nadir between the end of pregnancy and Day 14 of lactation and, like Crighton \& Lamming (1969), concluded that low pituitary stores of LH during early lactation were indicative of a suppression of both LH synthesis and release.

Although more recent studies of the responsiveness of the pituitary to GnRH stimulation have been somewhat equivocal, Bevers et al. (1981) reported an increase in the LH response to GnRH treatment as lactation progressed, consistent with the concept of an increase in the releasable pool of $\mathrm{LH}$ with increasing time post partum. Together with papers describing a gradual increase in endogenous circulating LH during lactation (see Britt et al., 1985, for review), and considered in the context of the data from other domestic species reviewed by Nett (1987), it would seem reasonable to conclude from these results that $\mathrm{LH}$ synthesis and release is also suppressed in the early post-partum period in the sow as a direct consequence of the previous gestation. A number of observations lead us to examine critically such conclusions.

Firstly, it is well established that LH is an essential luteotrophic signal in the sow during pregnancy and episodic LH secretion has been described throughout pregnancy by Parvizi et al. (1976) and by Ziecik et al. (1982). The active synthesis and release of LH in late gestation in itself suggests that chronic suppression of hypothalamic GnRH secretion and decreased pituitary sensitivity to $\mathrm{GnRH}$ is not a normal consequence of gestation in the sow. Secondly, a number of authors studying zero-weaned sows observed marked stimulation of ovarian follicular growth in at least a proportion of animals, as described earlier.

Although this increase in ovarian activity was variously associated with prolonged oestrus, anovulation and the formation of ovarian cysts, these data clearly indicate that an adequate gonado- 
trophic stimulus for follicular development may be present immedately after parturition in the absence of suckling. This further suggests that gestation has no latent effect on the synthesis and release of gonadotrophins. Kunavongkrit et al. (1983a) substantiated the earlier data of Parvizi $e t$ al. (1976) in showing that active secretion of LH occurred in the early post-partum period, although the frequency of sampling in each study did not permit an effective characterization of the pattern of LH secretion at this time. De Rensis (1989) compared LH secretory activity and follicular development in groups of normally suckled (control) sows and in sows weaned $6 \mathrm{~h}$ after the birth of the last piglet (zero weaned). Although there was considerable between-sow variability in LH secretory activity in the immediate post-partum period, a considerable proportion of sows released $\mathrm{LH}$ in a manner characteristic of the follicular phase of the oestrous cycle, irrespective of treatment (see Fig. 2). In zero-weaned sows the persistence of this pattern of LH release was invariably associated with enhanced follicular development and, in animals with the highest circulating concentration of $\mathrm{LH}$, follicular growth and steroidogenic activity surpassed that seen in normal preovulatory follicles, suggesting that cystic follicles were already developing. In suckled sows LH secretion was eventually suppressed in the later period of sampling (54-78 h post partum), suggesting that suckling per se is the primary cause of $\mathrm{GnRH}$ and hence $\mathrm{LH}$ inhibition in the lactating post-partum sow. The timing of this suppression also suggests that the neuroendocrine reflexes triggered by suckling, rather than the metabolic demands of milk synthesis (which would be low at this time), probably mediate these inhibitory effects.

Finally, a consideration of the temporal relationships between prolactin and $\mathrm{LH}$ changes in this study (see Fig. 3) suggest that prolactin does not have a direct role in the regulation of LH secretion in the early post-partum period. If the suckling-induced suppression of LH release is accepted as the predominant cause of lactational anoestrus in the sow, emphasis should be given to elucidating fully the physiological mechanisms involved in mediating this inhibition at the hypothalamic level. As described above, the endogenous opiates are certainly implicated.

More recently, as discussed earlier, Armstrong et al. (1988a) compared the LH response to naloxone treatment and weaning and concluded that the opioids act in association with other factors in mediating the suckling-induced suppression of gonadotrophins. The identity of these other factors is uncertain but recent studies at Nottingham have further defined the relationships between suckling intensity, milk production, gonadotrophin secretion and ovarian function in the lactating sow. Consistent with reports of a beneficial effect of fractionated or split-weaning on reproductive function (see Britt et al., 1985, for review), Shaw (1984) observed that a reduction in litter size on Day 21 of lactation resulted in a marginal stimulation of follicular development determined in vitro on Day 28 . However, there was no evidence of a persistent change in gonadotrophin secretion in the $24-\mathrm{h}$ period before final weaning at Day 28 and only a transient increase in FSH, and no effect on $\mathrm{LH}$, in the 12 -h period after initial litter size reduction. As in the later study of lactating sows by Foxcroft et al. (1987), these results suggest that the stimulation of follicular development in lactation and after weaning is not necessarily associated with a measurable change in circulating gonadotrophins.

This possibility was further examined in a study by Grant (1989) in which the ovarian and endocrine status of control, lactating sows (suckling at least 10 piglets) was compared with sows in which litter size was reduced to 5 piglets from Day 14 to Day 21 of lactation, with (covered) or without (split-weaned) covering of the anterior three pairs of teats. In-vitro analysis of ovarian development on Day 21 established that split-weaning alone enhanced the development of ovarian follicles, with a further increase in follicular development as a result of teat coverage. LH secretion in control sows was unchanged over the 48 -h period in which the combination of covering and split-weaning resulted in a chronic increase in $\mathrm{LH}$ release (see Fig. 4). Although some split-weaned sows also showed a persistent $\mathbf{L H}$ response to litter-size reduction, only a transient increase in $\mathbf{L H}$ secretion occurred in others, and there was no consistent relationship between the magnitude of the immediate $\mathrm{LH}$ response to split-weaning and the increase in follicular development measured 7 days later. 


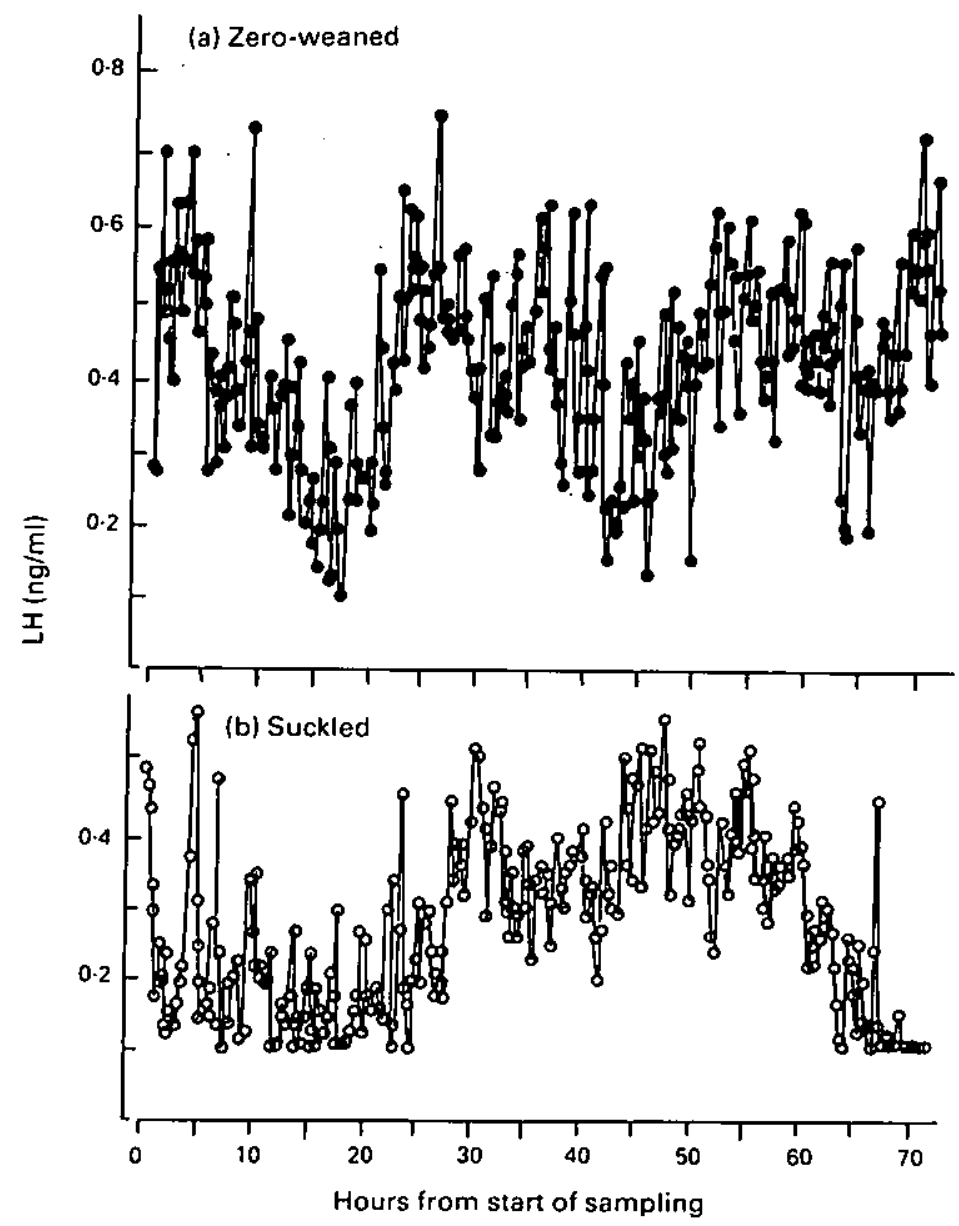

Fig. 2. Plasma LH changes in primiparous sows determined by sampling at 15 -min intervals for $72 \mathrm{~h}$, starting $6 \mathrm{~h}$ after the birth of the last piglet. (a) A zero-weaned sow from which the litter was removed at the start of sampling; (b) a control sow suckling a litter of at least 10 piglets. (Drawn from data of de Rensis, 1989.)

Studies involving the manipulation of litter size and teat a vailability also provide a better understanding of the relative importance of the metabolic demands of lactation and the neuroendocrine response to suckling as mediators of lactational anoestrus. In the study of Grant (1989), the mean ( \pm s.e.m.) total litter weights of piglets weaned by Day 21 of lactation (an indication of total lactation milk yield) from sows in the control, split-weaned and covered groups were, $50.6 \pm 1.6$, $48.2 \pm 1.3$ and $48.9 \pm 1.7 \mathrm{~kg}$, respectively; the catch-up growth of the smaller piglets sucking the sow between Days 14 and 21 of lactation after split-weaning (achieved by sucking multiple teats or maximizing milk production from the teats left available) therefore compensated for the early removal of the heavier litter-mates on Day 14. There was therefore little apparent change in the metabolic demands on the sows in each treatment group. The differential responses of the sows to treatment, in terms of gonadotrophin secretion and ovarian development, therefore appear to be primarily mediated through differences in the amount of afferent neural stimulation generated by suckling. 


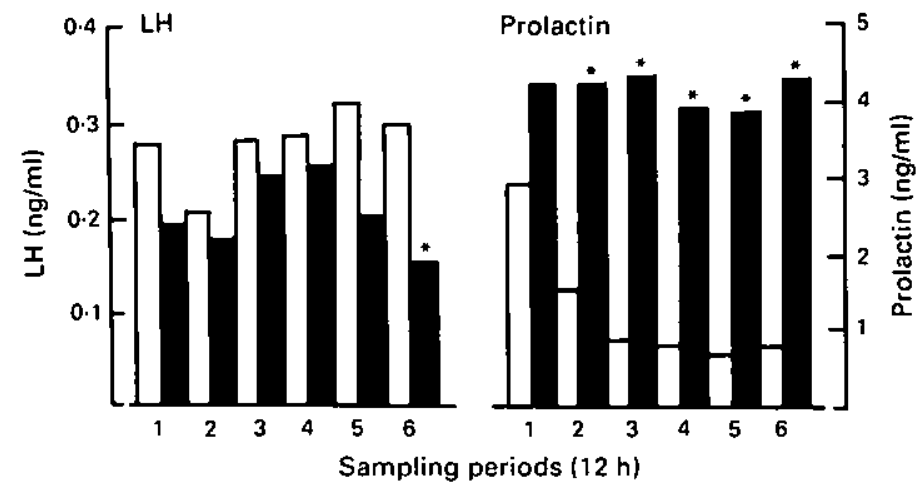

Fig. 3. Mean plasma $\mathrm{LH}$ and prolactin concentrations in groups of zero-weaned $(\mathrm{N}=8$, open bars) and suckling ( $N=9$, solid bars) control sows in the 72 -h period starting $6 \mathrm{~h}$ after birth of the last piglet. Means were derived from 15-min samples during each of six 12-h periods. $* P<0.05$. (Drawn from data of de Rensis, 1989.)
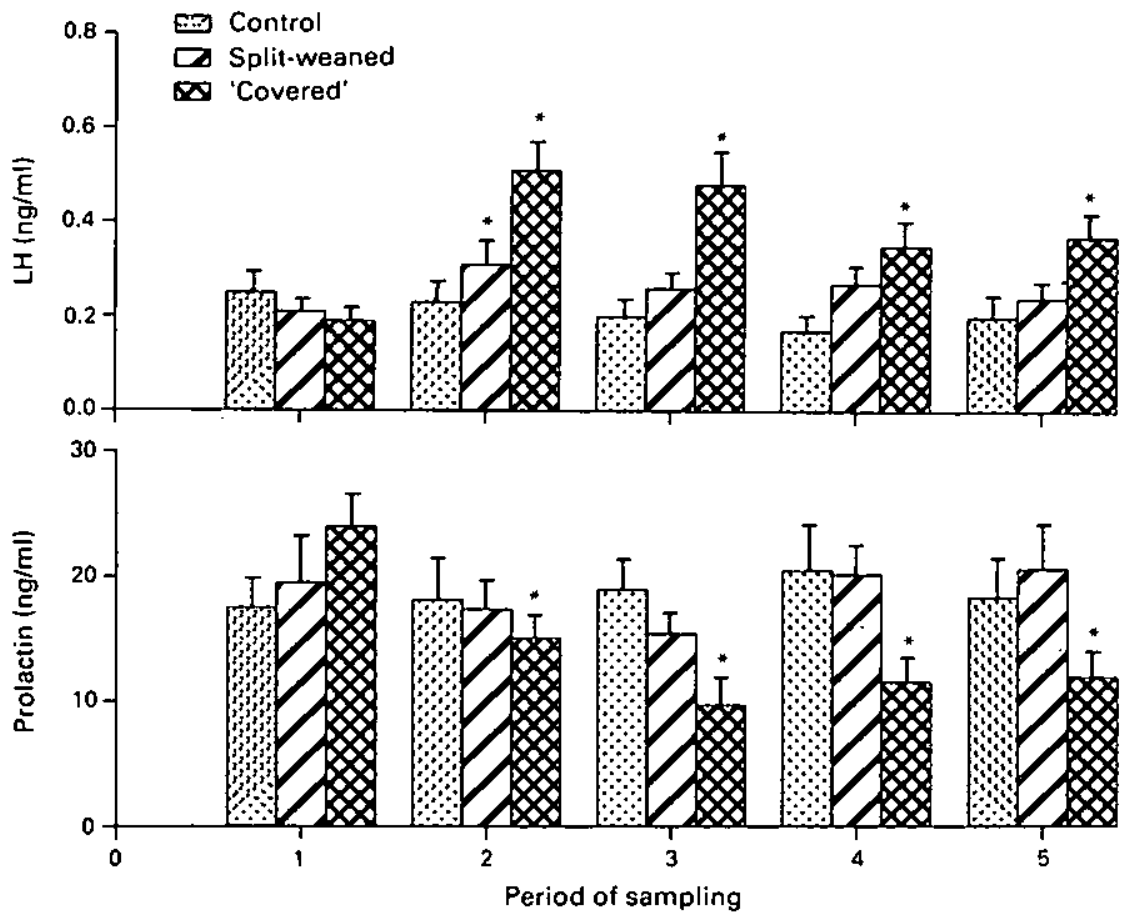

Fig. 4. Mean (土s.e.m.) plasma LH and prolactin concentrations derived from frequent samples in consecutive 12-h periods before (Period 1 ) and after (Periods $2-5$ ) treatment of control sows $(\mathrm{N}=7)$ suckling litters of at least 8 piglets throughout, split-weaned sows $(\mathrm{N}=8)$ in which litter size was reduced to the lightest 5 piglets at the end of Period 1 , and covered sows $(N=8)$ which were split-weaned in association with the physical masking of the three anterior pairs of teats. ${ }^{*} P<0.05$ compared to Period 1. (Drawn from data of Grant, 1989.) 


\section{Suckling-induced endocrine changes and their role in the regulation of reproductive activity}

The neuroendocrine events triggered by suckling appear to be an important component of the inhibitory mechanisms inducing lactational anoestrus. It is not surprising therefore that the potential role of those hormones released in response to suckling, as mediators of the inhibitory effects of suckling, have been studied in some detail. Evidence for the suckling-induced release of prolactin in the sow was first reported by van Landeghem \& van de Wiel (1978) and later confirmed by Kendall et al. (1983) and S. Okrasa, G. Kotwica, R. Ciereszko \& L. Dusza (personal communication). Plasma prolactin increases rapidly during the period of nuzzling and teat massage before milkletdown and peak prolactin concentrations (representing up to an 8 -fold increase above basal levels) are observed some 10-15 min later. Prolactin concentrations then return to basal levels about $30-40 \mathrm{~min}$ after the start of suckling. For much of lactation, suckling frequency serves to maintain a chronic elevation in circulating prolactin. A reduction in litter size during lactation (from 10 to 5 piglets) is not apparently associated with any persistent proportional reduction in plasma prolactin concentrations (Shaw, 1984; Grant, 1989), suggesting that the afferent input from a limited number of piglets is sufficient to exceed the threshold for blocking the dopaminergic inhibition of prolactin secretion. Complete separation of the litter, however, on either a temporary (partial weaning) or permanent basis, results in a precipitous decline in prolactin secretion to basal levels within $6 \mathrm{~h}$ (Shaw, 1984).

The gradual decline in prolactin secretion in late lactation appears to result from a gradual decrease in suckling frequency, rather than a diminution of the prolactin response to suckling (S. Okrasa, G. Kotwica, R. Ciereszko \& L. Dusza, personal communication).

A number of different experimental techniques have been used to elucidate possible inhibitory effects of prolactin on reproductive function and this work has been reviewed previously by van de Wiel et al. (1985) and by Dusza \& Tilton (1990). Available evidence suggests that prolactin or the regulators of prolactin secretion play some part in mediating the inhibitory effects of suckling on reproduction, affecting ovarian function indirectly through a partial inhibition of gonadotrophin and particularly LH secretion. Prolactin may also exert effects directly on the ovary.

The detailed characteristics of suckling-induced oxytocin release were described by Forsling $e t$ al. (1979) and Eltendorff et al. (1982). Afferent stimulation due to nuzzling and teat massage triggers the milk ejection reflex and culminates in the release of a single small pulse of oxytocin approximately $30 \mathrm{sec}$ before milk letdown; in 'incomplete' sucklings (Ellendorff el $\mathrm{al}$. , 1982) the threshold for the release of oxytocin is not attained and behavioural responses by the sow and milk letdown are not observed. The effects of oxytocin apparently decline as lactation progresses because (1) the oxytocin response to suckling decreases (Forsling et al., 1979; S. Okrasa, G. Kotwica, R. Ciereszko \& L. Dusza, personal communication) and (2) the suckling interval increases. This would lead to a concomitant decline in any inhibitory effect of oxytocin. The earlier studies of Peters et al. (1968, 1969a) suggested a possible role for oxytocin in the regulation of FSH secretion and ovarian function but Ellendorff $e t$ al. (1985) have failed to demonstrate consistently an inhibitory effect of oxytocin in the weaned sow.

The magnitude of the suckling-induced release of oxytocin after manipulating litter size and hence suckling intensity between Days 14 and 21 of lactation was assessed by Grant (1989). The combination of litter-size reduction and teat covering for 7 days did not result in any reduction in the amplitude of the suckling-induced surge of oxytocin (see Fig. 5). As with prolactin secretion, therefore, it appears that relatively few piglets are able to provide sufficient afferent stimulation to trigger milk letdown and that once this occurs oxytocin is released in an 'all-or-none' manner. This situation contrasts to the close relationship between the amount of afferent stimulation and the amount of oxytocin released in laboratory species. Although no consistent effects of changes in endogenous oxytocin secretion or of exogenous oxytocin treatment on reproductive function have 
been established, this does not preclude involvement of other mediators of the milk ejection reflex in the modulation of reproductive function. For instance, evidence from other species has linked oxytocin release to the release of prolactin (Samson et al., 1986) and the concurrent increase in oxytocin and prolactin in response to suckling observed by S. Okrasa, G. Kotwica, R. Ciereszko \& L. Dusza (personal communication) would be consistent with experimental evidence for a similar relationship in the sow. The co-localization of endogenous enkephalins in oxytocin-secreting neurones has also been reported (Martin \& Voigt, 1981). Similar mechanisms in the sow would provide the basis for a link between activation of the milk-ejection reflex and an opioidergic inhibition of GnRH secretion.

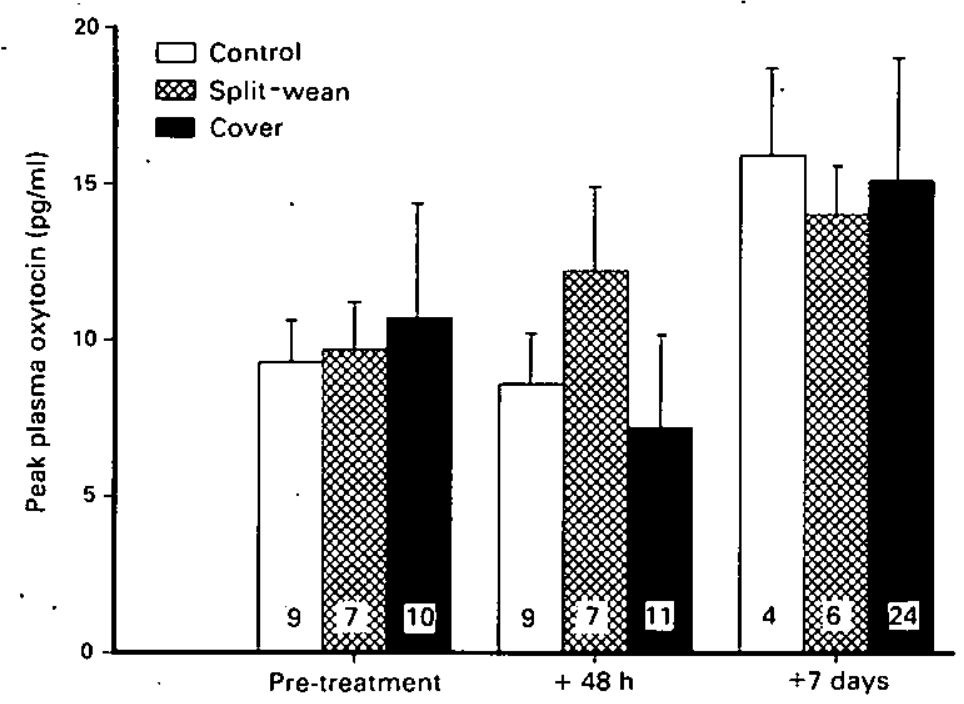

Fig. 5. Mean ( \pm s.e.m.) peak plasma oxytocin measured during periods of suckling in the sows for which data are shown in Fig. 4. Samples were assayed from one or more suckling incidents · per sow of the day before applying treatments, on the day after treatment and again 7 days later. Numbers indicate no. of suckling incidents for which samples were analysed. No effect of treatment on peak oxytocin levels was established. (Drawn from data of Grant, 1989.)

Contradictory evidence has been presented for the possible involvement of relaxin in the control of lactation and reproductive activity post partum. The work of Summerlee et al. (1984) demonstrated a feedback relationship between relaxin and oxytocin as one component of the milk-ejection reflex. A similar role for relaxin in the sow has been proposed on the basis of data describing suckling induced release of relaxin during lactation (Afele et al., 1979; Whitely et al., 1985). The concomitant release of progesterone and relaxin in the latter study suggested that the regressing corpora lutea of pregnancy could be the source of both hormones and still therefore endocrinologically active. However, in other experiments neither Sherwood et al. (1981) nor Kendall $e t$ al. (1983) have been able to confirm an increase in plasma relaxin at the time of suckling. Such differences are unresolved. In some cases it has been suggested that management of sows and the frequency of sampling may have been inappropriate to demonstrate short-term episodes of relaxin secretion (see Whitely et al., 1985); on the other hand, in other experiments purporting to show the episodic release of relaxin in response to suckling and exogenous oxytocin administration the data are at variance with the reported circulating half-life of relaxin (see discussion by Sherwood, 1982).

The proposal that the regressing corpora lutea of pregnancy are the source of relaxin during lactation seems consistent with evidence for a gradual decline in luteal relaxin concentrations from early to late lactation (Anderson et al., 1973; see Whitely et al., 1985) and preliminary evidence for the continued expression of relaxin mRNA at Day 2 of lactation (Bagnell et al., 1988). Recent 
studies to provide rigorous experimental evidence for (1) changes in the immunohistochemical localization of relaxin in the corpora lutea of sows at different stages of lactation, (2) the sucklinginduced release of relaxin from the same animals in vivo and (3) oxytocin-induced release of relaxin from luteal tissue in vitro confirmed a rapid decrease in the intensity of immunohistochemical staining for relaxin but provided no evidence for relaxin or progesterone secretion by the regressing corpora lutea in vivo or in vitro (R. H. F. Hunter, F. de Rensis, G. R. Foxcroft, P. A. DenningKendalt \& D. C. Wathes, unpublished observations). Further verification of earlier studies therefore seems necessary in order to establish unequivocally a role for relaxin during lactation in the sow.

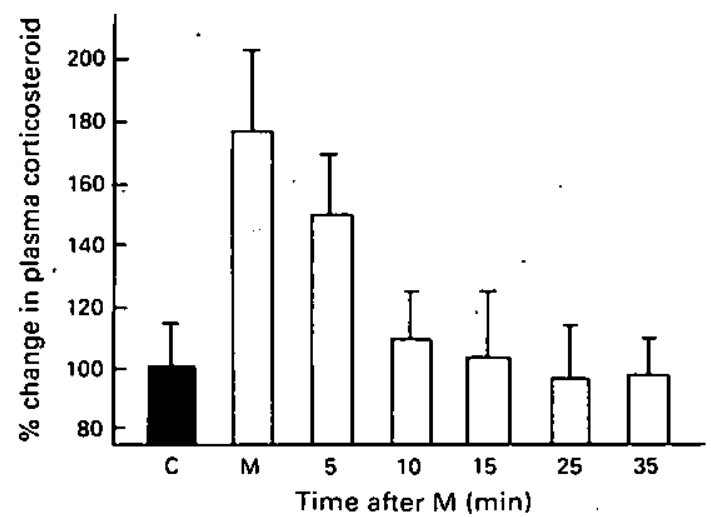

Fig. 6. Changes in plasma corticosteroid concentrations in sows $(\mathrm{N}=8)$ in comparison to samples collected before suckling (C); increases during teat massage (M) and 5, 10, 15, 25 and 35 min later are expressed as a percentage of pre-suckling levels (taken as $100 \%$ ) (S. Okrasa, G.

Kotwica, R. Cieresżko \& L. Dusza, personal communication).

The data shown in Fig. 6 also provide evidence for a suckling-induced increase in plasma corticosteroids in the sow. Suck ling was associated with a measurable increase in corticosteroids in $64 \%$ of suckling episodes studied in 4 sows on Days 5, 10, 15, 20,25 and 30 of lactation; moreover, the corticosteroid response appeared to increase as lactation progressed. Although it was suggested that such changes may be related to the degree of suckling stress experienced by the sow, some relationship to the metabolic (catabolic) state of the sow also seems likely.

\section{Conclusions}

The available data suggest that major increases in episodic LH secretion in lactation in the presence of adequate plasma concentrations of FSH will promote follicular growth. Such changes can be induced either by substantially reducing the inhibitory effects of suckling/lactation or by treating sows with exogenous GnRH or gonadotrophin. Less substantial reductions in suckling activity may still promote initial follicular development but as such responses are not always dependent on an increase in gonadotrophin secretion, other factors appear to mediate the suckling-induced suppression of ovarian function. If this is correct, then the treatment of lactating sows with exogenous gonadotrophin or $\mathrm{GnRH}$, in the absence of a reduction in the suckling stimulus, may not elicit maximal ovarian responses.

Oestrogen secretion in lactation appears to be variable but can be at extremely high levels in mid-lactation and this may be a stress-related phenomenon with adrenal involvement. The origins of lactational oestrogen and its interaction with other endocrine signals require further study. Ostensibly the sow is under acute stress both at parturition and at weaning as evidenced by elevated 
cortisol concentrations. The current practice of imposing abbreviated lactations may therefore compound these two potent stressors and the net result is that the sow is less able to reproduce successfully in the following pregnancy.

Increases in oxytocin, prolactin, corticosteroids, progesterone and oxytocin in response to suckling have the potential to affect reproductive activity in lactation. There is convincing experimental evidence for an involvement of prolactin in GnRH and LH inhibition and for possible regulation at the ovarian level. Evidence for an involvement of plasma corticosteroids in the regulation of reproduction has accumulated from other studies in pigs and similar effects may be present in lactation. Convincing experimental evidence for a role for relaxin and oxytocin in the regulation of reproduction in lactation is still needed.

The results of Grant (1989) suggest that the relationships between the level of afferent stimulation applied at suckling and the threshold for activating those hypothalamic/pituitary pathways controlling the release of oxytocin, prolactin, and GnRH vary considerably. The threshold for stimulating oxytocin release appears to be the lowest in that milk ejection and the pattern of oxytocin release were unchanged in split-weaned and teat-covered sows in which chronic changes in prolactin and LH secretion were observed. However in some split-weaned sows LH secretion was affected in the absence of any change in plasma prolactin, suggesting in turn that the neural threshold for activating the inhibitory dopaminergic pathways controlling prolactin secretion is lower than for that which exerts an inhibitory effect on GnRH synthesis and release.

One important practical consequence of these observations is that the considerable reduction in litter size that is probably required to enhance gonadotrophin secretion may have only a relatively small impact on the lactogenic effects of prolactin and the efficiency of the milk ejection reflex. In the short term, therefore, no reduction in milk synthesis or release should result from the practice of split-weaning.

Parts of the work reported in this paper received financial support from the Meat and Livestock Commission and from the Agricultural and Food Research Council. We thank Dr S. Okrasa for making unpublished material available for use in this review and to Pamela Blythe for typing and collating the manuscript.

\section{References}

Afele, S., Bryant-Greenwood, G.D., Chamley, W.A. \& Dax, E.M. (1979) Plasma relaxin immunoactivity in the pig at parturition and during nuzzling and suckling. J. Reprod. Fert. 56, 451-457.

Ahrens, M. \& Schlegel, W. (1975) Superposition of lactation and pregnancy by administration of gonadotropic hormones. Mschr. VelMed. 30, 736-739.

Anderson, L.L., Ford, J.J., Melampy, R.M. \& Cox, D.F. (1973) Relaxin in porcine corpora lutea during pregnancy and after hysterectomy. Am. J. Physiol. 225, $1215-1219$.

Armstrong, J.D., Kraeling, R.R. \& Britt, J.H. (1988a) Effects of naloxone or transient weaning on secretion of LH and prolactin in the lactating sow. $J$. Reprod. Ferl. 83, 301-308.

Armstrong, J.D., Kraeling, R.R. \& Britt, J.H. (1988b) Morphine suppresses luteinising hormonc concentrations in transiently weaned sows and delays onset of oestrus after weaning. J. Anim. Sci. 66, 2216-2223.

Ash, R.W. \& Heap, R.B. (1975) Oestrogen, progesterone and corticosteroid concentrations in peripheral plasma of sows during pregnancy, parturition, lactation and after weaning. $J$. Endocr. 64, 141-154.
Bagnell, C.A., Ali, S.M. \& McMurtry, J.P. (1988) In situ localization of relaxin messenger RNA in the pig corpus luteum in the cycle, pregnancy and lactation. Biol. Reprod. 38 (Suppl. 1), 179, abstr.

Barb, C.R., Kraeling, R.R., Rampacek, G.B. \& Whisnant, C.S. (1986) Opioid inhibition of LH secretion in the post-partum lactating sow. Biol. Reprod. 35, 368-371.

Barb, C.R., Kroeling, R.R., Rampacek, G.B. \& Leshin, L.S. (1987) Opioid modulation of follicle stimulating hormone (FSH) and prolactin (PRL) secretion in the postpartum sow. Adv. exp. Med. Biol. 219, 647-652.

Bevers, M.M., Willemse, A.H., Kruip, Th.A.M. \& van de Wiel, D.F.M. (1981) Prolactin levels and the LH response to synthetic LHRH in the lactating sow. Anim. Reprod. Sci. 4, 155-163.

Britt, J.H., Armstrong, J.D., Cox, N.M. \& Esbenshade, K. (1985) Control of follicular development during and after lactation in the sow. J. Reprod. Fert., Suppl. 33, 37-54.

Brown, J.B., Falconer, C.W.A. \& Strong, J.A. (1959) Urinary oestrogens of adrenal origin in women with breast cancer. J. Endocr. 19, 52-63. 
Burger, J.F. (1952) Sex physiology of pigs. Onderstepoort J. vet. Res., Suppl. 2, 3-218.

Buttle, H.L. (1987) Some effects of total mastectomy upon subsequent reproduclive performance in sows. Br. vet. J. 143, 318-327.

Cox, N.M. \& Britt, J.H. (1982) Pulsatile administration of gonadotropin releasing hormone to lactating sows: endocrine changes associated with induction of fertile estrus. Biol. Reprod. 27, 1126-1137.

Cox, N.M., Ramirez, J.L., Matamoros, I.A. \& Bennett, W.A. (1988) Estrogen induces estrus unaccompanied by a preovulatory surge in luteinizing hormone in suckled sows. Biol. Reprod. 38, 592-596.

Crighton, D.B. (1970) Induction of pregnancy during lactation in the sow. J. Reprod. Fert. 22, 223-231.

Crighton, D.B. \& Lamming, G.E. (1969) The lactational anoestrus of sows; the status of the anterior pituitaryovarian system during lactation and after weaning. $J$. Endocr. 43, 507-519.

de Rensis, F. (1989) Reproductive physiology of the early post-parnum sow. M. Phil. thesis, University of Nottingham.

Duggan, R.T., Bryant, M.J. \& Cunningham, F.J. (1982) Gonadotrophin, lotal oestrogen and progesterone concentrations in the plasma of lactating sows with particular reference to lactational oestrus. J. Reprod. Fert. 64, 303-313.

Dusza, L. \& Tilton, J.E. (1990) Role of prolactin in the regulation of ovarian function in pigs. $J$. Reprod. Fert. Suppl. 40, 33-45.

Edqvist, L.E., Einarsson, S. \& Settergren, 1. (1974) Ovarian activity and peripheral plasma levels of oestrogen and progesterone in the lactating sow. Theriogenology 1, 43-49.

Edwards, S. (1982) The endocrinology of the post-partum sow. In Control of Pig Reproduction, pp. 439-458. Eds D. J. A. Cole \& G. R. Foxcroft. Butterworths, London.

Ellendorf, F., Forsling, M.L. \& Poulain, D.A. (1982) The milk ejection reflex in the pig. J. Physiol. Lond. 333, 577-594.

Ellendorff, F., Elsaesser, F., Parvizi, N. \& Smidt, D. (1985) Endocrine interactions during lactational anestrus in sows. In Endocine Causes of Seasonal and Lactational Anestrus in Farm Animals, pp. 145-153. Eds F. Ellendorff \& F. Elsaesser, Martinus Nijhoff, Dordrecht.

Elliot, J.1., King, G.J. \& Robertson, H.A. (1980) Reproductive performance in the sow subsequent to weaning piglets at birth. Can. J. Anim. Sci. 60, $65-71$.

Elsaesser, F. \& Parvizi, N. (1980) Partial recovery of the stimulatory oestrogen feedback action on LH release during late lactation in the pig. $J$. Reprod. Fert. 59, 63-67.

Forsling, M.L., Taverne, M.A.M., Parvizi, N., Elsaesser, F., Smidt, D. \& Ellendorf, F. (1979) Plasma oxytocin and background steroid levels during late pregnancy, parturition and lactation in the miniature pig. $J$. Endocr. 82, 61-69.

Foxcroft, G.R. (1985) Follicular dynamics and its endocrine control in the sow. In Follicular Growth and Ovulation Rate in Farm Animals, pp. 191-205. Eds J. Roche \& D. O'Callaghan. Martinus Nijhoff, Amsterdam.
Foxcroft, G.R., Shaw, H.J., Hunter, M.G., Booth, P.J. \& Lancaster, R.T. (1987) Relationship between luteinizing hormone, follicle-stimulating hormone, prolactin secretion and ovarian follicular development in weaned sows. Biol. Reprod. 36, 175-191.

Grant, S.A. (1989) Control of follicular development in the cyclic gilt and weaned sow. Ph.D. thesis, University of Notlingham.

Guthrie, H.D., Pursel, V.G. \& Frobish, L.T. (1978) Atlempts to induce conception in lactating sows. $J$. Anim. Sci. 47, 1145-1151.

Hausler, C.L., Hodson, H.H., Kuo, D.C., Kinney, T.J. Rauwolf, V.A. \& Strack, L.E. (1980) Induced ovulation and conception in laclating sows. J. Amim. Sci. 50, 773-778.

Hillbrand, F.W. \& Elsaesser, F. (1983) Concentration of progesterone in the backfat of pigs during the oestrous cycle and after ovariectomy. J. Reprod. Fert. $69,73-80$.

Hughes, P.E. \& Varley, M.A. (1980) Reproduction in the Pig. Butterworths, London.

Kendall, J.Z., Richards, G.E. \& Shih, L.N. (1983) Effect of haloperidol, suckling, oxylocin and hand milking on plasma relaxin and prolactin concentration in cyclic and lactating pigs. $J$. Reprod. Fert. 69, 271-277.

Kirkwood, R.N., Lapwood, K.R., Smith, W.C. \& Anderson, I.L. (1984) Plasma concentrations of LH, prolactin. oestradiol-17 $\beta$ and progesterone in sows weaned after lactating for 10 or 35 days. $J$. Reprod. Fert. $\mathbf{7 0}$, 95-102.

Kunavongkrit, A. (1984) Clinical, morphological and endocrinological studies in primiparous posipartum sows. Ph.D. Thesis, Sveriges Lantbruksuniversitet. Uppsala, Sweden.

Kunavongkrit, A., Kindahl, H. \& Madej, A. (1983a) Clinical and endocrinological studies in primiparous zero weaned sows. (2) Hormonal patterns of normal cycling sows after zero-weaning. Zentbl. VetMed. A 30, 616-624.

Kunavongkrit, A., Edqvist, L.E. \& Einarsson, S. (1983b) Clinical and endocrinological studics in zero-weaned sows. (3) Hormonal patterns of ovarian disorders due to zero-weaning. Zentbl. VetMed. A 30,625-636.

Martin, A. \& Voigt, K.H. (1981) Enkephalins coexist with oxytocin and vasopressin in nerve terminals of rat hypothalamus. Nature, Lond. 239, 502-504.

Martinat-Botte, F. (1975) Induction of gestation during lactation in the sow. Amm/s Biol. anim. Biochim. Biophys. 15, 369-374.

Mattioli, M., Conte, F., Galeati, G. \& Seren, E. (1986) Effect of naloxone on plasma concentration of prolactin and luteinizing hormone in the lactating sow. $J$. Reprod. Fert. 76, 167-173.

McDonald, C.L. (1975) A study of the immediate postpartum period of the sow. M.Phil. thesis. University of Nottingham.

Melampy, R.M., Henricks, D.M., Anderson, L.L., Chen, C. \& Schultz, l.R. (1966) Pituitary follicle stimulating hormone and luteinizing hormone concentrations in pregnant and lactating pigs. Endocrinology 78, 801-804.

Nett, T.M. (1987) Function of the hypothalamichypophysial axis during the post-partum period in ewes and cows. J. Reprod. Fert., Suppl. 34, 201-203. 
Newton, E.A., Stevenson, J.S., Minton, J.E. \& Davies, D.L. (1987) Endocrine changes before and after weaning in response to boar exposure and altered suckling in sows. J. Reprod. Fert. 81, 599-609.

Palmer, W.M., Teague, H.S. \& Venzke, W.G. (1965) Histological changes in the reproductive tract of the sow during lactation and early post weaning. $J$. Anim. Sci. 24, 541-545.

Parvizi, N., Elsaesser, F., Smidt, D. \& Ellendorff, F. (1976) Plasma luteinizing hormone and progesterone in the adult female pig during the oestrous cycle, late pregnancy and lactation, and after ovariectomy and pentobarbitone treatment. J. Endocr. 69, 193-203.

Petchey, A.M. \& English, P.R. (1980) A note on the effects of boar presence on the performance of sows and their litters when penned in groups in late laclation. Anim. Prod. 31, 107-109.

Peters, J.B., Short, R.E., First, N.L. \& Casida, L.E. (1968) Ovarian and pituitary gland changes in hysterectomized postpartum sows treated with FSH and oxytocin. J. Anim. Sci. 29, 20-24.

Peters, J.B., First, N.L. \& Casida, L.E. (1969a) Effect of piglet removal and oxytocin injection on ovarian and pituitary changes in mammilectomized post-partum sows. J. Anim. Sci. 28, 537-541.

Peters, J.B., Short, R.E., First, N.L. \& Casida, L.E. (1969b) Attempts to induce fertility in post-partum sows. J. Anim. Sci. 29, 20-24.

Prime, G.R., Varley, M.A. \& Symonds, H.W. (1988) The effect of food intake in lactation and early pregnancy on plasma progesterone concentrations and prolificacy in multiparous sows. Anim. Prod. 44, 499, abstr.

Ramirez, J.L., Cox, N.M. \& Bennett, W.A. (1985) Characterization of estrus and ovulation in lactating sows given pulsatile gonadotropin-rcleasing hormone terminated at estrus or $24 \mathrm{~h}$ later. J. Anim. Sci. 61 (Suppl. 1), 44, abstr.

Rojanasthien, S.A.M., Lundeheim, N. \& Einarsson, S. (1987) Luteinizing hormonc response to different doses of synthetic gonadotrophin releasing hormone during early and late lactation in primiparous sows. Anim. Reprod. Sci. 13, 299-307.

Rowlinson, P. \& Bryant, M.J. (1982) Lactational oestrus in the sow. 3. The influence of group housing, boar presence and feeding level upon the occurrence of oestrus in lactating sows. Anim. Prod. 34, 283-290.

Samson, W.K., Michael, D.L. \& McCann, S.M. (1986) Evidence for a physiological role of oxytocin in the control of prolactin secretion. Endocrinology 119, $554-560$.

Schumm, H.R., Bostedt, H., Matzke, P., Bogner, H., Averdunk, G. \& Berner, H. (1979) Farrowing rates after oestrus induction during lactation in sows. Bayer. landw. Jb. 56, $118-126$.

Shaw, H.J. (1984) Control of ovarian function in lacrating and weaned sows. Ph.D. thesis, University of Nottingham.

Shearer, l.J., Purvis, K., Jenkin, G. \& Haynes, N.B. (1972) Peripheral plasma progesterone and oestradiol-17 $\beta$ levels before and after puberty in gilts. $J$. Reprod. Fert. 30, 347-360.
Sherwood, O.D. (1982) Relaxin at parturition in the pigs. In Conirol of Pig Reproduction, pp. 343-375. Eds D. J. A. Cole \& G. R. Foxcroft. Butterworths, London.

Sherwood, O.D., Nara, B.S., Welk, F.A., First, N.L. \& Rutherford, J.E. (1981) Relaxin levels in maternal plasma of pigs before, during and after parturition and before, during and after suckling. Biol. Reprod. $25,65-71$.

Stevenson, J.S. \& Britt, J.H. (1980) Luteinising hormone, total oestrogens and progesterone secretion during lactation and after weaning in sows. Theriogenology 14, 453-462.

Stevenson, J.S., Cox, N.M. \& Britt, J.H. (198I) Role of the ovary in controlling luteinising hormone, follicle stimulating hormone and prolactin secretion during and after lactation in pigs. Biol. Reprod. 24, $341-353$

Summerlee, A.J.S., O'Byrne, K.T., Paisley, A.L., Breeze, M.F. \& Porter, D.G. (1984) Relaxin affects the central control of oxytocin release. Nature. Lond. 309, 372-374.

Svajgr, A.J., Hays, V.W., Cromwell, G.L. \& Dutt, R.H. (1974) Effect of lactation duration on reproductive performance of sows. J. Anim. Sci. 38, 100-105.

van de Wiel, D.F.M., Booman, P., Willemse, A.H. \& Bevers, M.M. (1985) Relevance of prolactin to lactational and post weaning anoestrus in the pig. In Endocrine Causes of Seasonal and Lactational Anoestrus in Farm Animals, pp. 154-164. Eds F. Ellendorff \& F. Elsaesser. Martinus Nijhoft, Dordrecht.

van Landeghem, A.A.J. \& van de Wiel, D.F.M. (1978) Radioimmunoassay for porcine prolactin plasma levels during lactation, suckling and weaning and after TRH administration. Acta endocr., Copenh. 88, 653-667.

Varley, M.A. (1982) The time of weaning and its effects on reproductive function. In Control of Pig Reproduction, pp. 459-478. Eds D. J. A. Cole \& G. R. Foxcroft. Butterworths, London.

Varley, M.A. \& Atkinson, T. (1985) Weaning at birth: the effect on reproduction of the sow. Anim. Prod. 41, 375-382.

Varley, M.A. \& Cole, D.J.A. (1978) Studies in sow reproduction. 6 . The effect of lactation length on pre-implantation losses. Anim. Prod. 27, 207-214.

Varley, M.A., Atkinson, T. \& Ross, L.N. (198I) The effect of lactation length on the circulating concentrations of progesterone and oestradiol in the early weaned sow. Theriogenology 16, 179-184.

Varley, M.A., Peaker, R.E. \& Atkinson, T. (1984) Eftect of lactation length of the sow on plasma progesterone, oestradiol-17\% and embryo survival. Anim. Prod. 38, 113-119.

Whitely, J., Wilcox, D.L., Hartmann, P.E., Yamamoto, S.Y. \& Bryant-Greenwood, G.D. (1985) Plasma relaxin levels during suckling and oxylocin stimulation in the lactating sow. Biol. Reprod. 33, 705-7/4.

Ziecik, A., Tilton, J.E., Weigl, R. \& Williams, G.L. (1982) Plasma luteinizing hormone during pregnancy in the pig. Anim. Reprod. Sci. 5, 213-218. 